\title{
Use of intravenous cannulae by junior hospital doctors
}

\author{
S.M. Yentis \\ Department of Anaesthesia, Charing Cross and Westminster Hospitals, Fulham Palace Road, London W6 \\ $8 R F, U K$
}

\begin{abstract}
Summary: One hundred junior hospital doctors were surveyed to investigate their use of intravenous cannulae. Anaesthetists inserted more cannulae per day than non-anaesthetists and were more likely to use local anaesthetic and wear gloves, although most doctors never or rarely did so. Anaesthetists were also more knowledgeable than non-anaesthetists about the sizes of cannulae they used and the sizes available, although there was considerable ignorance overall in this regard. Many doctors regularly place themselves at risk and expose their patients to unnecessary pain during intravenous cannula insertion, and have little knowledge about the cannulae they use.
\end{abstract}

\section{Introduction}

Intravenous (i.v.) cannulae are crucial to the administration of parenteral fluids and thus to the management of hypovolaemia. However, there is usually little formal education for medical students and junior doctors about use of i.v. cannulae, most junior doctors learning as they 'go along'. The level of knowledge of i.v. cannulae amongst junior hospital doctors has not previously been studied. Anaesthetists are routinely responsible for perioperative i.v. fluid replacement and are thus more directly involved with the immediate consequences of volume loss and replacement than doctors in other specialties. This survey was conducted to investigate the use of i.v. cannulae amongst junior hospital doctors (anaesthetists and non-anaesthetists).

\section{Methods}

A questionnaire (see Appendix) was shown to all house officers, senior house officers (SHOs), registrars and senior registrars in the following specialties in two different district general hospitals: accident and emergency (A\&E), anaesthetics, general medicine, general surgery, obstetrics and gynaecology and orthopaedics.

The doctors were divided into two groups: anaesthetists and non-anaesthetists. The numbers of cannulae inserted were compared using the Mann-Whitney $U$-test, and other data were ana-

Correspondence: S.M. Yentis, F.R.C.Anaes, Chelsea and Westminster Hospital, 369 Fulham Road, London SW10 9NH, UK.

Accepted: 25 September 1992 lysed using chi-square analysis or Fisher's exact test as appropriate. A value of $\boldsymbol{P}$ of 0.05 was used to denote statistical significance.

\section{Results}

All of the 100 doctors approached responded. There were 25 house offices, 44 SHOs, 29 registrars and two senior registrars. The number of cannulae inserted, use of local anaesthetic and gloves, choice of cannula for the patient described and knowledge of flow rates and cannula size are shown in Table I. Suggested flow rates for the cannulae varied from $10 \mathrm{ml} /$ minute to $2,000 \mathrm{ml} /$ minute; these values were compared with flow rates for cannulae obtained under standard conditions. ${ }^{1}$ Two doctors (both non-anaesthetists) said they would insert two $16 \mathrm{G}$ cannulae.

There were no differences in use of cannulae between surgical and medical specialties or according to seniority of doctor, apart from a greater number of cannulae inserted by non-anaesthetic house officers and SHOs compared with registrars and senior registrars (median (range) $2(0-6)$ compared with $1(0-4)$, respectively; $P<0.001)$. Median (range) estimated initial success rates for insertion of cannulae were similar in all specialties and grades $(90(10-100 \%))$, although the two doctors that reported initial success rates of under $70 \%$ were both non-anaesthetist pre-registration house officers. Sixty-eight per cent of doctors always used alcohol skin cleansing swabs before insertion, whilst $17 \%$ never or rarely $(>20 \%$ of occasions) used them; there was no difference between specialties in this regard. 
Table I Answers to questions concerning the use of intravenous cannulae

\begin{tabular}{|c|c|c|c|c|}
\hline & Anaesthetists & Non-anaesthetists & Total & $\mathbf{P}$ \\
\hline Number of respondents & 17 & 83 & 100 & \\
\hline Number of cannulae/day (median (range)) & $8(2-15)$ & $2(0-6)$ & & $<0.001$ \\
\hline \multicolumn{5}{|l|}{ Use of local anaesthetic* } \\
\hline Never & $2(12)$ & $71(86)$ & 73 & $<0.001$ \\
\hline $1-20 \%$ occasions & $7(41)$ & $5(6)$ & 12 & 0.001 \\
\hline$>20 \%$ occasions & $8(47)$ & $7(8)$ & 15 & 0.001 \\
\hline \multicolumn{5}{|l|}{ Use of gloves* } \\
\hline Never & $3(18)$ & $47(57)$ & 50 & 0.008 \\
\hline $1-20 \%$ occasions & $11(65)$ & $23(28)$ & 34 & 0.008 \\
\hline$>20 \%$ occasions & $3(18)$ & $13(16)$ & 16 & NS \\
\hline \multicolumn{5}{|l|}{ Cannula selected for hypothetical patient* } \\
\hline Venflon (Viggo) selected & $12(71)$ & $80(96)$ & 92 & 0.007 \\
\hline \multicolumn{5}{|l|}{ Size chosen } \\
\hline $18 \mathrm{G}$ & 0 & $10(12)$ & 10 & NS \\
\hline $16 \mathrm{G}$ & $5(29)$ & $56(67)$ & 61 & 0.008 \\
\hline $14 G$ & $12(71)$ & $17(20)$ & 29 & 0.001 \\
\hline Selected by colour without knowing & & & & \\
\hline correct size & $4(24)$ & $61(73)$ & 65 & $<0.001$ \\
\hline $\begin{array}{l}\text { Flow rate correct to within } 50 \% \text { actual } \\
\text { value }^{1}\end{array}$ & $7(41)$ & $9(11)$ & 16 & NS \\
\hline \multicolumn{5}{|l|}{ Biggest cannulae available* } \\
\hline $18 \mathrm{G}$ & 0 & $4(5)$ & 4 & NS \\
\hline $16 \mathrm{G}$ & 0 & $35(42)$ & 35 & 0.001 \\
\hline $14 \mathrm{G}$ & $11(65)$ & $29(35)$ & 40 & 0.04 \\
\hline $12 \mathrm{G}$ & $4(24)$ & $12(14)$ & 16 & NS \\
\hline $10 \mathrm{G}$ & $2(12)$ & $3(4)$ & 5 & NS \\
\hline
\end{tabular}

*Number $(\%)$. NS = not significant.

\section{Discussion}

The findings of this survey support the generally held impression that anaesthetists insert more cannulae than non-anaesthetists and are more likely to use local anaesthetics. They are also more likely to wear gloves and select large cannulae. However, they are only slightly more knowledgeable about cannula sizes, and are not significantly more knowledgeable about flow rates through cannulae (which are marked on the packaging of several makes of cannula including Venflons).

That $73 \%$ of doctors never use local anaesthetics, even for insertion of $16 \mathrm{G}$ and $14 \mathrm{G}$ cannulae, is disturbing. Pain increases with size of cannula, ${ }^{2-4}$ and a recent study has reported that subcutaneous injection of lignocaine is less painful than insertion of $18 \mathrm{G}, 20 \mathrm{G}$ or $22 \mathrm{G}$ cannulae. ${ }^{4}$ A common reason given for not using local anaesthetic is that is makes subsequent cannulation more difficult. However, a local anaesthetic often makes cannulation easier, because the patient is more comfortable and thus more likely to keep still. The greater use of local anaesthetics by anaesthetists may reflect their increased familiarity with these agents and their particular concern with pain, although it is difficult to see how any doctor cannot be concerned by the pain inflicted by a large i.v. cannula.
The wearing of gloves is a sensible precaution $\stackrel{\frac{\AA}{\perp}}{\circ}$ against blood-borne infections. Only $16 \%$ of doc- $\overrightarrow{\vec{A}}$ tors in the present study wear gloves on more than 3 $20 \%$ of occasions, whilst $50 \%$ of doctors never wear them. This suggests a lack of concern which: has been previously demonstrated with respect to contamination in operating theatres ${ }^{5}$ and immuni- 3 . zation against hepatitis. ${ }^{6}$ Impaired manual dexterity is often given as a reason for not wearing. gloves, but those that regularly wear them wouldo dispute this. ${ }^{5}$ The incidence of injury or contamination was not assessed in the present study, although의 a recent American paper reported an $18 \%$ inci- $\rightarrow$ dence of contamination during peripheral venous cannulation by anaesthetists. ${ }^{7}$

Use of cleansing solution such as propyl alcohol ${ }^{\circ}$ or chlorhexidine prior to insertion of i.v. cannulae ${ }^{N}$ is widely performed as it reduces skin and cannula $N$ contamination with bacteria and thrombophlebi-O tis. ${ }^{8,9}$ The commonest reason given for not cleaningo the skin in this study was that it is ineffective, but respondents were unable to support this claim.

The choice of large (16G or $14 \mathrm{G})$ cannulae in $\square$ most cases for the imaginary patient described is reassuring, although there was considerable igno- $\stackrel{\mathbb{Q}}{\oplus}$ rance about the sizes of cannulae used. The choice $\stackrel{\mathbb{Q}}{\Omega}$ 
of cannulae may be influenced by the availability of certain types and sizes of cannulae in the hospitals studied. For example, Venflons are widely available in the wards and A\&E departments of many hospitals, but other types of cannulae are commonly used in operating theatres. Venflons are often considered earlier to insert than other cannulae, although this has not been investigated. Referral to cannulae by colour alone is only appropriate for a particular make of cannulae until a colour coding standard for i.v. cannulae is generally adopted. ${ }^{10}$ It might be argued that knowledge of flow rates through cannulae is not important. However, the difference between flow rates through cannulae of different sizes may be extremely important in a hypovolaemic patient requiring rapid volume replacement. For example, for Venflons under standard conditions, flow rates of $80 \mathrm{ml} /$ minute (18G (green)), $180 \mathrm{ml} /$ minute $(16 \mathrm{G}$ (grey)) and $270 \mathrm{ml} /$ minute (14G (brown)) are possible, with up to twice these values possible if pressure infusors are used. ${ }^{1}$ Thus for severe hypovolaemia, the largest possible cannula should be

\section{References}

1. Kestin, I.G. Flow through intravenous cannulae. Anaesthesia 1987, 42: 67-70.

2. Nott, M.R. \& Peacock, J.L. Relief of injection pain in adults. Anaesthesia 1990, 45: 772-774.

3. Ferrante, F.M., Steinbrook, R.A., Hughes, N., Kistler, P. \& Manzi, D. $1 \%$ lidocaine with and without sodium bicarbonate for attenuation of pain of skin infiltration and intranveous catheterization. Anesthesiology 1991, 75: A736.

4. Harrison, N., Langham, B.T. \& Bogod, D.G. Appropriate use of local anaesthetic for venous cannulation. Anaesthesia 1992, 47: 210-212.

5. Harrison, C.A., Rogers, D.W. \& Rosen, M. Blood contamination of anaesthetic and related staff. Anaesthesia 1990 , 45: 831-833.

6. Burden, A.D. \& Whorwell, P.J. Poor uptake of hepatitis B immunization amongst hospital-based health care staff. Postgrad Med J 1991, 67: 256-258.

\section{Appendix}

The following questions were asked in the questionnaire:

1 . What is your grade and specialty?

2. How many i.v. cannulae do you insert per day, on average?

3. How often are you successful first time?

4. How often do you use local anaesthetic in awake patients (excluding for cannulae smaller than $21 \mathrm{G}$ used for induction of anaesthesia)?

5. How often do you wear gloves? used. Several manufacturers supply $13 \mathrm{G}$ and $12 \mathrm{G}$ cannulae, and one supplies a $10 \mathrm{G}$ cannula. ${ }^{1}$

None of the doctors questioned had received any formal training in insertion of i.v. cannulae. However, in the discussions prompted by this survey, several commented that they would change their practice, particularly with regard to use of local anaesthetic and gloves, and selection of larger cannulae.

This study demonstrates a need for education of junior hospital doctors about the use of i.v. cannulae, a task which is routinely performed many times a day. Although anaesthetists are more likely to use local anaesthetic and gloves, and are more knowledgeable about i.v. cannulae than nonanaesthetists, there is considerable room for improvement in all specialties.

\section{Acknowledgement}

I am grateful to the junior doctors of the Hillingdon Hospital, Middlesex, and the Royal Surrey County Hospital, Guildford, for their help with this study.

7. Kristensen, M.S., Sloth, E. \& Jensen, T.K. Relationship between anesthetic procedure and contact of anesthesia personnel with patient body fluids. Anesthesiology 1991, 73: 619-624.

8. Norwood, S., Ruby, A., Civetta, J. \& Cortes, V. Catheterrelated infections and associated septicaemia. Chest 1991, 99: 968-975.

9. Smallman, L., Burdon, D.W. \& Alexander-Williams, J. The effect of skin preparation and care on the incidence of superficial thrombophlebitis. Br J Surg 1980, 67: 861-862.

10. Tordoff, S.G. \& Sweeney, B.P. Intravenous cannulae colour coding. Anaesthesia 1990, 45: 399-400.

6. How often do you clean the skin with alcohol?

7. What size, type and colour of cannula would you use for a patient with a perforated viscus admitted via A\&E?

8. What is the approximate maximal flow rate (in $\mathrm{ml} /$ minute) through the cannula selected in the previous answer?

9. What is the biggest peripheral i.v. cannula available of any make? 